\title{
A Study on the Effect of Valeric Acid in Alzheimer's Induced Rats by the Estimation of A $\beta$ 1-42 Biomarker
}

\author{
Blessina Sugandhi Dulla ${ }^{1}$ Bindhu S. ${ }^{1}$ Leena Pramod K. ${ }^{2}$
}

1 Department of Anatomy, Yenepoya Medical College, Yenepoya (deemed to be) University, Mangalore, Karnataka, India

2 Department of Forensic Medicine and Toxicology, Yenepoya Medical College, Yenepoya (deemed to be) University, Mangalore,

Karnataka, India

J Health Allied Sci ${ }^{\mathrm{NU}}$ 2022;12:134-138.

\begin{abstract}
Address for correspondence Bindhu S., MSc, PhD, PGDBEME, Department of Anatomy, Yenepoya Medical College, Yenepoya (deemed to be) University, Mangalore 575018, Karnataka, India (e-mail: Bindhunair@yenepoya.edu.in).
\end{abstract}
Abstract
Keywords
- Alzheimer's disease
- amyloid $\beta$ 1-42
- elevated plus maze
- Hebb Williams maze
- valeric acid

The effect of valeric acid on the behavior of Alzheimer's disease (AD)-induced rats by aluminum chloride $(100 \mathrm{mg} / \mathrm{kg}$ body weight) was assessed using elevated plus maze (EPM) and the Hebb Williams maze (HWM). Amyloid $\beta$ 1-42(A $\beta 1-42)$ biomarker was estimated by ELISA. In this study, valeric acid-treated rats were compared with those treated with piracetam $(200 \mathrm{mg} / \mathrm{kg})$, rivastigmine $(0.5 \mathrm{mg} / \mathrm{kg})$, and the results showed the rats treated with valeric acid had a very less transfer latency of EPM and HWM when compared with other standard drugs. In addition, valeric acid-treated rats showed reduced levels of amyloid $\beta 1-42$ biomarker in the plasma. Hence, this study found that valeric acid may be suggested as a better drug for Alzheimer's disease.

\section{Introduction}

The ability of an individual to record sensory stimuli, information, and events and keep them over short or long periods and recollect the same later when needed is called memory. Lower retention, poor recollection, and slow recall are common problems with people going through stress and tension. Age, emotions, and stress are the conditions that possibly lead to amnesia, memory loss, anxiety, dementia, high blood pressure, or more ominous threats such as schizophrenia and Alzheimer's disease (AD). The central cholinergic system plays an important role in memory and learning. Cognitive deterioration occurring in patients with $\mathrm{AD}$ is correlated with the progressive loss of cholinergic neurons and a subsequent reduction in the levels of acetylcholine in the brain. ${ }^{1,2}$ The prevalence of $A D$ has been increasing. The occurrence of moderate to severe dementia in different groups of the population is $\sim 5 \%$ in the population older than 65 years of age, 20 to $40 \%$ in the general popula- tion older than 85 years of age globally. ${ }^{3}$ The increasing incidence of $\mathrm{AD}$ is a social concern and financial burden for society. Memory-enhancing drugs are costly and have minimal efficacy. Hence, there is a need to develop an alternative and economical agent with high efficacy. Herbs are the source of most drugs. ${ }^{4}$

The perennial flowering plant Valeriana officinalis is used widely in different countries to treat insomnia and anxiety due to its sedative effects, ${ }^{5}$ its extracts contain free amino acids such as gamma aminobutyric acid (GABA) and other substances such as isovalerate. ${ }^{6}$ Many studies have reported that the effects of this plant when combined with other drugs to treat various central nervous system (CNS) diseases, most of them interfere with GABA neurotransmitters. ${ }^{5-8}$ Valeric acid is a key component of $V$. officinalis and prevents GABA from being broken down in the brain. ${ }^{9}$ It elevates the GABA levels through the inactivation of $\alpha$-ketoglutarate dehydrogenase $^{10}$ and reduces GABA degradation by mediating the GABA transaminase and thereby inhibiting GABA catabolism.
DOI https://doi.org/ $10.1055 / \mathrm{s}-0041-1736274$ ISSN 2582-4287.

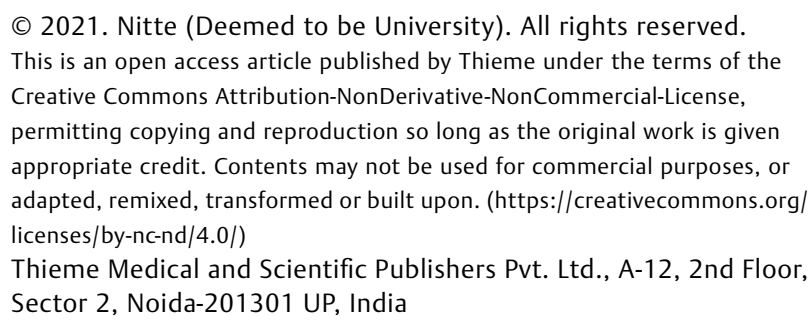


It functions as a GABA-A agonist by increasing the response of GABA-A receptor II. ${ }^{11,12}$ The administration of $\mathrm{AlCl}_{3}$ (100 $\mathrm{mg} / \mathrm{kg}$ b.wt) for 42 days orally resulted in the loss of spatial as well as contextual memory in rats. ${ }^{13}$ Bhattacharjee et al. Exley reported that aluminum is a potential causative agent of $\mathrm{AD} .^{14,15}$ Aluminum accretion in the hippocampus causes anomalous (amyloid $\beta$ ) $A \beta$ accumulation and neuroinflammation according to some epidemiological and animal studies. The stimulation of microglia is the main event in brain neuroinflammation. It could result in hippocampus-dependent memory, learning, and memory problems. ${ }^{16}$

This pre-clinical study is focused to identify a better drug for $\mathrm{AD}$ over the pre-existing drugs and aims to find the behavioral activity of valeric acid in the treatment of Ad rats in comparison with that of the standard drugs such as piracetam and rivastigmine.

Piracetam and rivastigmine are established therapeutic agents used to treat AD. Studies have shown that piracetam increases mitochondrial function, plasticity, synaptic markers, oxidative stress, neuronal outgrowth, cognition, and also cerebral microcirculation. ${ }^{17}$

Rivastigmine increased the neurotrophic soluble amyloid precursor protein- $\alpha(s A P P-\alpha)$ and decrease $A \beta$ secretion. Rivastigmine treatment enhances neuronal $\beta$ amyloid precursor protein (SAPP) in degenerating neuronal cultures. It preserves neuronal morphology and enhances cell viability in neurodegenerating cultures. ${ }^{18}$ By enhancing sAPP production, rivastigmine might protect the neurons from neurite retraction $^{19}$ and apoptosis. ${ }^{20}$

\section{Materials and Methods}

This study was conducted in the Department of Anatomy, Yenepoya Medical College, Mangalore, in 2018, after presenting it in the 20th IAEC meeting and getting approval from the Institutional Animal Ethics Committee (YU/IAEC/4/2018). The study was conducted in accordance with the Committee for the Purpose of Control and Supervision of Experiments on Animals (CPCSEA), Government of India guidelines.

\section{Animals}

Forty-two male Wistar albino rats weighing 220-250 g (4-6 months age group) were used. They were housed in polypropylene cages at $22 \pm 1^{\circ} \mathrm{C}$ and kept under adequate environmental conditions. All rats were divided into seven groups, and six rats were assigned to each group for scientific and statistical analyses. ${ }^{21}$

\section{Materials}

Aluminum chloride salt ( $500 \mathrm{~mL}$ bottle) and valeric acid solution were purchased from Sri Durga Laboratory, Mangalore, Karnataka. Piracetam and rivastigmine tablets were purchased from Ganesh Medical Store, Mangalore.

\section{Drug Interventional Studies}

Forty-two rats were divided into seven groups as shown in - Fig. 1. Each group contained six rats. The control group (Group 1) was administered distilled water orally and

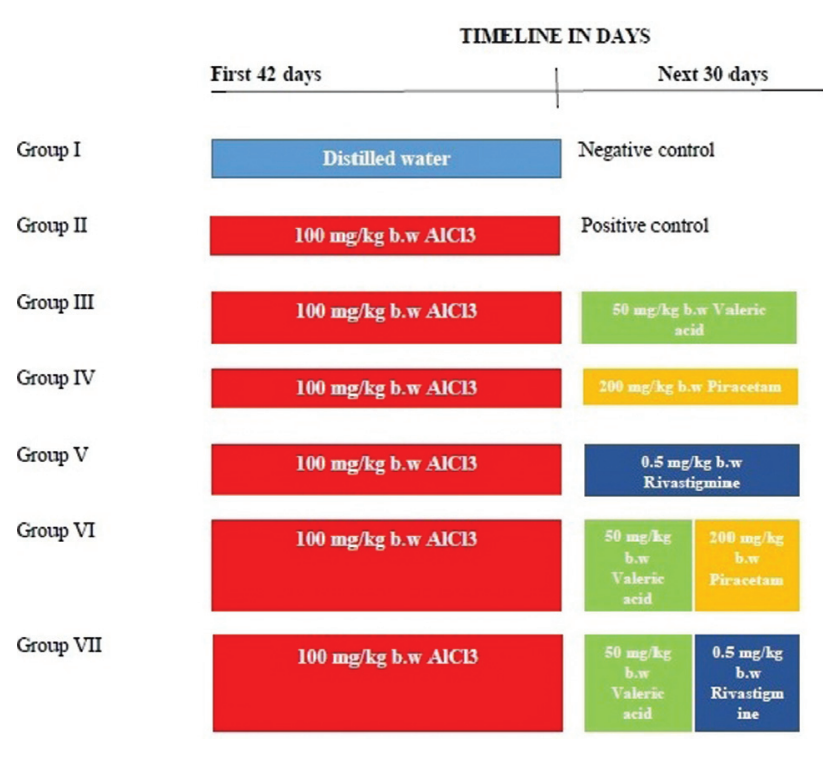

Fig. 1 Experimental animal groups piracetam*-administered after $30 \mathrm{~min}$, rivastigmine ${ }^{*}$-administered after 30 min. $^{26}$

Group 2 rats were administered aluminum chloride $\left(\mathrm{AlCl}_{3}\right)$ at a dose of $100 \mathrm{mg} / \mathrm{kg}$ b.wt. for 42 days orally to induce $\mathrm{AD} .^{13} \mathrm{AD}$ was also induced in the remaining rats (Group 3 to Group 7) with the same dose of $\mathrm{AlCl}_{3}$. After 42 days, elevated plus maze (EPM) and Hebb Williams maze (HWM) models were used to evaluate the memory and learning behavior of aluminum chloride-treated rats in comparison with the control group rats. After inducing $A D$, Group 3 rats were treated with valeric acid $(50 \mathrm{mg} / \mathrm{kg}$ b.w.t), ${ }^{22}$ Group 4 rats were treated with piracetam (200 $\mathrm{mg} / \mathrm{kg}$ b.w.), ${ }^{23}$ Group 5 rats were treated with rivastigmine $\left(0.5 \mathrm{mg} / \mathrm{kg}\right.$ b.w.) ${ }^{24}$ Group 6 rats were treated with valeric acid + piracetam, and Group 7 rats were treated with valeric acid + rivastigmine ${ }^{25}$ for 30 days to treat the cognitive impairment in rats induced by aluminum chloride. The memory-enhancing effect of valeric acid in comparison with the other standard drugs was assessed after the treatment and confirmed by EPM and HWM tests.

\section{Background of Experimental Rats}

The study was performed on Wistar albino rats weighing $\sim 220-250 \mathrm{~g}$. The rats were randomized into seven different treatment groups as shown in - Fig. 1. Rats used in the study were bred in the Liveon Biolabs, Bangalore (registration number - 1610/ROBiBt/S/2012/CPCSEA). They were housed in polypropylene cages containing husk to keep them dry throughout the experiments. Four rats were kept in one cage. The identification of rats was done by marking them on the head, body, and tail and with cage numbers. Animals were housed under standard laboratory conditions such as room temperature $\left(22 \pm 1^{\circ} \mathrm{C}\right)$ with 12 hours light and dark cycle. They were fed with rat chow. All behavioral experiments were performed in a room adjacent to that where the rats were monitored under the same conditions of temperature and humidity and light cycle. 


\section{Behavioral Experiments}

\section{Elevated Plus Maze}

Elevated plus maze served as the exteroceptive behavior model to evaluate learning and memory in rats. This model has two open arms $(30 \times 5 \mathrm{~cm})$ and two covered arms $(30 \times 5 \times 12 \mathrm{~cm})$ expanded from a central platform $(5 \times 5 \mathrm{~cm})$ and the maze was lifted to a height of $50 \mathrm{~cm}$ from the floor. At the time of the experiment, each rat was placed at the end of an open arm, opposite from the central platform. Transfer latency (TL) is the time (in seconds) taken by the animal to move from the open arm into one of the closed arms with its four legs inside. TL was recorded on the initial day (training session) for each animal. The rats were allowed to walk around the maze for another 2 min and then taken back to their home cage. The retention of the learnedtask (memory) was observed after a complete day. ${ }^{26}$

\section{Hebb-Williams Maze}

This is an incentive-based exteroceptive behavioral model employed for determining the spatial working memory of rats. It has three components: the animal chamber (or start box) attached to the middle chamber (or exploratory area) and a reward chamber at the other end of the maze in which the food (reward) is kept. All three components are supplied with guillotine removable doors. On the initial day, the rats were placed in the start box and the door was opened to smooth the progress of the entry of the animals into the next chamber. The door of the start box was immediately closed after the rats moved into the next chamber to prevent back entry. For each animal, the time taken by it to reach the reward chamber from the start box was recorded (i.e., TL in seconds) on the first two days (training session). Each animal was permitted to explore the maze for $3 \mathrm{~min}$ with all the doors opened before returning to its home cage. The retention of this learned task (memory) was examined $24 \mathrm{~h}$ after the trial days. ${ }^{27}$

Estimation of Amyloid $\beta$ 1-42 (A $\left.\boldsymbol{\beta}_{1-42}\right)$ Levels in Plasma The presence of extracellular plaques composed mainly of 42 amino acid amyloid $\beta$ peptide $\left(A \beta_{1-42}\right)$ is one of the pathological traits of $A D .^{28}$ Amyloid $\beta 1-42$ biomarker was estimated in blood plasma using an ELISA kit (GeneTex, Sri Durga Laboratory, Mangalore). For plasma collection, the blood was collected in tubes containing EDTA as an anticoagulant. These plasma samples were kept at $-80^{\circ} \mathrm{C}$ until biochemical analysis after centrifugation (2000 rpm, $\left.+4^{\circ} \mathrm{C}, 10 \mathrm{~min}\right)$.

\section{Statistical Analysis}

The data, expressed as mean \pm standard deviation, were subjected to one-way analysis of variance (ANOVA) followed by Tukey-Kramer test. $P<0.05$ was considered to be statistically significant.

\section{Results and Discussion}

\section{Transfer Latency on Elevated Plus Maze}

In the present study, the TL (-Fig. 2) on EPM was marked in all the groups. Group 1 (negative control + distilled water)

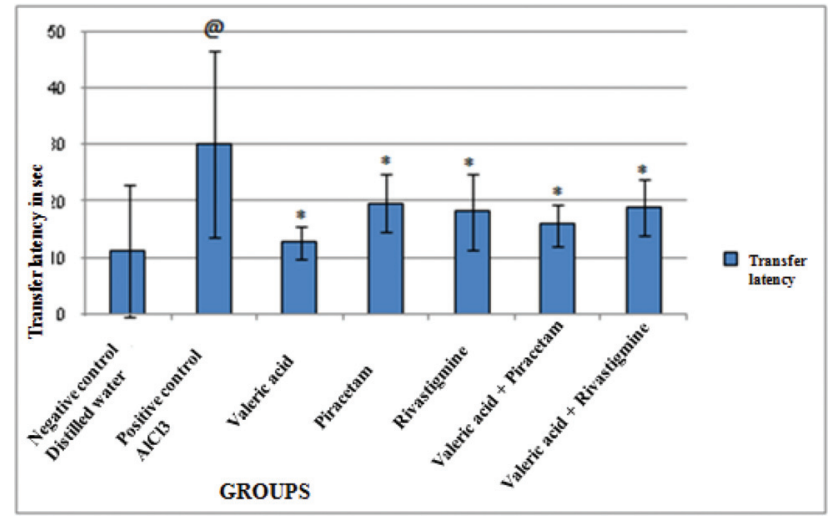

Fig. 2 Effect of valeric acid on the memory of Alzheimer's diseaseinduced rats using the elevated plus maze. The values are means \pm SEM $(n=6) ;{ }^{@} p<0.05$ (versus negative control group), ${ }^{*} p<0.05$ (versus positive control group).

rats showed a TL of only $10 \mathrm{~s}$ showing good memory retention in the EPM. Group 2 rats (positive control $+\mathrm{AlCl}_{3}$ ) showed an increase in the TL period showing impairment in memory retention. Group 3 (valeric acid) showed a decrease in the TL period showing reversal of impairment caused by $\mathrm{AlCl}_{3}$ and improved memory retention in the experimental group. Group 4 (piracetam) and Group 5 (rivastigmine) rats treated with standard drugs showed reduced TL period. Group 6 (valeric acid + piracetam) showed improvement in memory retention in $\mathrm{AlCl}_{3}$-induced rats. Group 7 (valeric acid + rivastigmine) also showed a reduced TL period.

Lin et al and Thippeswamy et al reported that the TL in EPM was considerably enhanced in the group of rats treated with aluminum chloride when compared with the normal control group rats. ${ }^{29,30}$ Similarly, the present study showed increased TL in EPM test in aluminum chloride-administered rats. When these rats were treated with respective drugs, Group 3 rats treated with valeric acid showed marked improvement in memory with decreased TL period, indicating the reversal of $\mathrm{AlCl}_{3}$-induced neurotoxicity in comparison to Group 4 (piracetam), Group 5 (rivastigmine), Group 6 (valeric acid + piracetam), and Group 7 (valeric acid + rivastigmine).

\section{Transfer Latency on Hebb-Williams Maze}

Transfer latency (-Fig. 3) on HWM was marked in all groups. Group 1 (negative control + distilled water) rats showed a TL of only $12 \mathrm{~s}$ showing good memory retention in HWM. Group 2 rats (positive control $+\mathrm{AlCl}_{3}$ ) showed an increase in TL period indicating impairment in memory retention. Group 3 (valeric acid) and Group 6 (valeric acid + piracetam) showed a decrease in TL period showing reversal of impairment caused by $\mathrm{AlCl}_{3}$ and improved memory retention in the experimental groups. Reduction in the TL period was less in Group 5 (rivastigmine) followed by Group 7 (valeric acid + rivastigmine) and Group 4 (piracetam).

Auti et al reported cognitive impairments in aluminum chloride-induced rats and the TL period in HWM was 


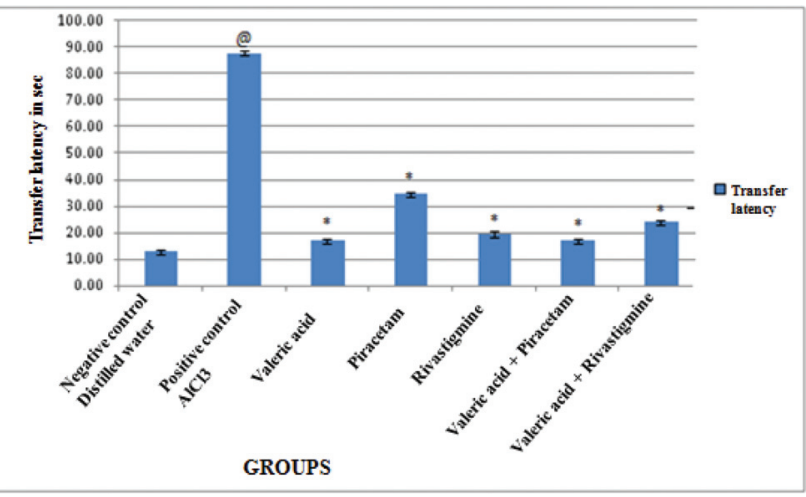

Fig. 3 Effect of valeric acid on the memory of Alzheimer's diseaseinduced rats using the Hebb Williams maze. The values are means \pm SEM $(n=6) ;{ }^{@} p<0.05$ (versus negative control group), ${ }^{*} p<0.05$ (versus positive control group).

considerably increased in the group of rats treated with aluminum chloride when compared with the normal control group rats. ${ }^{31}$ Similarly, the present study showed increased TL in HWM test in aluminum chloride-administered rats. When these rats were treated with respective drugs, Group 3 (valeric acid) and Group 6 (valeric acid + piracetam) rats showed marked improvement in memory with decreased $\mathrm{TL}$ period indicating a reversal of $\mathrm{AlCl}_{3}$-induced neurotoxicity in comparison to the Groups 4 (piracetam), 5 (rivastigmine), and 7 (valeric acid + rivastigmine).

\section{Effect of Valeric Acid on the Level of Amyloid $\beta$ 1-42 in Plasma}

When amyloid $\beta 1-42$ was estimated in plasma using an ELISA kit, Group 1 (negative control + distilled water) rats showed a concentration of $1183.91 \pm 110.13 \mathrm{pg} / \mathrm{mL}$ showing a slight increase in the plasma (-Table 1). Matsubara et al and Fukumoto et al reported that the increase in age alone correlated with the increase in plasma amyloid $\beta$ levels in their studies. ${ }^{32,33}$ Group 2 rats (positive control $+\mathrm{AlCl}_{3}$ ) showed more levels of amyloid $\beta$ showing impairment in

Table 1 Effect of valeric acid on $A \beta_{1-42}$ levels in plasma

\begin{tabular}{|l|l|l|}
\hline S. No. & Groups & $\begin{array}{l}\text { Concentration } \\
\text { in } \mathrm{pg} / \mathrm{mL} \\
\text { (Mean } \pm \text { SD) }\end{array}$ \\
\hline 1 & $\begin{array}{l}\text { Distilled water } \\
\text { (negative control) }\end{array}$ & $1183.91 \pm 110.13$ \\
\hline 2 & $\begin{array}{l}\text { AlCl } \\
\text { (positive control) }\end{array}$ & $1693.58 \pm 212.56^{*}$ \\
\hline 3 & Valeric acid & $97.53 \pm 9.80^{* *}$ \\
\hline 4 & Piracetam & $72.36 \pm 14.19^{* *}$ \\
\hline 5 & Rivastigmine & $66.70 \pm 29.14^{* *}$ \\
\hline 6 & Valeric acid+ piracetam & $61.20 \pm 20.12^{* *}$ \\
\hline 7 & Valeric acid+ rivastigmine & $45.95 \pm 42.65^{* *}$ \\
\hline
\end{tabular}

Note: Values are means \pm SD. $(n=6) ;{ }^{*} p<0.05$ (versus positive control group), ${ }^{* *} p<0.05$ (versus negative control group). memory retention. Group 3 (valeric acid), Group 4 (piracetam), and Group 5 (rivastigmine) showed a marked reduction. Group 6 (valeric acid + piracetam) and Group 7 (valeric acid + rivastigmine) showed less levels compared with other treatment groups.

Liu et al found that the plasma levels of amyloid $\beta$ 1-42 increased in the $\mathrm{AD}$ patients. ${ }^{34}$ Similarly, $\mathrm{AlCl}_{3}$-treated rats showed a significant increase in the concentration of $A \beta_{1-42}$ as compared with that in the negative control group (distilled water) in the present study. When these rats were treated with respective drugs, Group 7 (valeric acid + rivastigmine) and Group 6 (valeric acid + piracetam) rats showed a marked reduction in the level of $A \beta_{1-42}$ showing improvement in the reversal of increased levels of $A \beta_{1-42}$ in $\mathrm{AlCl}_{3}$ induced $\mathrm{AD}$ rats.

The findings of this study showed aluminum chlorideinduced rats showed significant impairment in learning and memory in the positive control and experimental groups. A marked improvement in memory, reversing the impairment caused by aluminum chloride, was seen in valeric acidtreated rats in the EPM experiment. In the HWM experiment, valeric acid-treated rats and valeric acid in combination with piracetam showed promising results. The amyloid $\beta 1-42$ estimation in plasma however showed a marked reduction in amyloid $\beta$ deposits in valeric acid-treated rats in combination with rivastigmine when compared with other treated groups.

\section{Conclusion}

Valeric acid and its use in combination with standard drugs such as piracetam and rivastigmine appear to play a significant role in improving learning and memory in aluminum chloride-induced neural impairment. Thus, it would be worth exploring the potential of valeric acid in the treatment of neurodegenerative disorders such as AD.

\section{Limitations}

The EPM and HWM experiments were not recorded on the 15 th day of treatment with valeric acid (Group 3), piracetam (Group 4), rivastigmine (Group 5), valeric acid + piracetam (Group 6), and valeric acid + rivastigmine (Group 7).

Conflict of Interest

None declared.

\section{References}

1 Rahman H, Shaik HA, Madhavi P, Eswaraiah MC. A review: pharmacognostics and pharmacological profiles of Nardastachys jatamansi DC. Elixir Pharmacy 2011;39:5017-5020

2 Achliya G, Barabde U, Wadodkar S, Dorlel A. Effect of Bramhi Ghrita, an polyherbal formulation on learning and memory paradigms in experimental animals. Indian J Pharmacol 2004; 36(03):159-162

3 Hassan SK, Mandal US, Mondal DK, Jana D. A study on stress, anxiety and depression among caregivers of the patients with dementia in a tertiary care hospital in eastern India. Int J Sci Res 2020;9(01):7-9 
4 Veeresham C. Natural products derived from plants as a source of drugs. J Adv Pharm Technol Res 2012;3(04):200-201

5 Hadley S, Petry JJ. Valerian. Am Fam Physician 2003;67(08): $1755-1758$

6 Eadie MJ. Could valerian have been the first anticonvulsant? Epilepsia 2004;45(11):1338-1343

7 Krystal AD, Ressler I. The use of valerian in neuropsychiatry. CNS Spectr 2001;6(10):841-847

8 Ortiz JG, Nieves-Natal J, Chavez P. Effects of Valeriana officinalis extracts on [3H]flunitrazepam binding, synaptosomal [3H]GABA uptake, and hippocampal [3H]GABA release. Neurochem Res 1999;24(11):1373-1378

9 Neamati A, Chaman F, Hosseini M, Boskabady MH. The effects of Valeriana officinalis L. hydro-alcoholic extract on depression like behavior in ovalbumin sensitized rats. J Pharm Bioallied Sci 2014; 6(02):97-103

10 Luder AS, Parks JK, Frerman F, Parker WD Jr. Inactivation of beef brain alpha-ketoglutarate dehydrogenase complex by valproic acid and valproic acid metabolites. Possible mechanism of anticonvulsant and toxic actions. J Clin Invest 1990;86(05): 1574-1581

11 Monti B, Polazzi E, Contestabile A. Biochemical, molecular and epigenetic mechanisms of valproic acid neuroprotection. Curr Mol Pharmacol 2009;2(01):95-109

12 Frumkes TE, Nelson R. Functional role of GABA in cat retina: I. Effects of GABAA agonists. Vis Neurosci 1995;12(04):641-650

13 Ahmad Rather M, Justin Thenmozhi A, Manivasagam T, Dhivya Bharathi M, Essa MM, Guillemin GJ. Neuroprotective role of asiatic acid in aluminium chloride induced rat model of Alzheimer's disease. Front Biosci (Schol Ed) 2018;10:262-275

14 Bhattacharjee S, Zhao Y, Hill JM, Percy ME, Lukiw WJ. Aluminum and its potential contribution to Alzheimer's disease (AD). Front Aging Neurosci 2014;6:62

15 Exley C. What is the risk of aluminium as a neurotoxin? Expert Rev Neurother 2014;14(06):589-591

16 Oshima E, Ishihara T, Yokota O, et al. Accelerated tau aggregation, apoptosis and neurological dysfunction caused by chronic oral administration of aluminum in a mouse model of tauopathies. Brain Pathol 2013;23(06):633-644

17 Fessel J. Prevention of Alzheimer's disease by treating mild cognitive impairment with combinations chosen from eight available drugs. Alzheimers Dement (N Y) 2019;5:780-788

18 Bailey JA, Ray B, Greig NH, Lahiri DK. Rivastigmine lowers A $B$ and increases SAPP $\alpha$ levels, which parallel elevated synaptic markers and metabolic activity in degenerating primary rat neurons. PLoS One 2011;6(07):e21954

19 Copanaki E, Chang S, Vlachos A, et al. sAPPalpha antagonizes dendritic degeneration and neuron death triggered by proteasomal stress. Mol Cell Neurosci 2010;44(04):386-393

20 Brewer GJ, Torricelli JR, Evege EK, Price PJ. Optimized survival of hippocampal neurons in B27-supplemented Neurobasal, a new serum-free medium combination. J Neurosci Res 1993;35(05): 567-576

21 Charan J, Kantharia ND. How to calculate sample size in animal studies? J Pharmacol Pharmacother 2013;4(04):303-306

22 Vishwakarma S, Goyal R, Gupta V, Dhar KL. GABAergic effect of valeric acid from Valerianawallichii in amelioration of ICV STZ induced dementia in rats. Rev Bras Farmacogn 2016;26(04): 484-489

23 Varma RK, Singh L, Garg VK, Yadav P, Singh VK. Nootropic effect of vigna mungo (1.) hepper seeds extract in scopolamine induced amnesic rats. World J Pharm Sci 2016;5(12)1176-1192

24 Gawel K, Labuz K, Gibula-Bruzda E, et al. Cholinesterase inhibitors, donepezil and rivastigmine, attenuate spatial memory and cognitive flexibility impairment induced by acute ethanol in the Barnes maze task in rats. Naunyn Schmiedebergs Arch Pharmacol 2016;389(10):1059-1071

25 Abramets II, Kuznetsov YV, Evdokimov DV, Zaika TO. Piracetam potentiates neuronal and behavioral effects of ketamine. Res Pharmacol 2019;5(02):49-55

26 Deepa B, Divya B, Kumari NS, Sanjeev G, Rao S. Effect of electron beam radiations on memory in experimental animal models. Drug Invention Today 2012;4(09):444-446

27 Vasudevan M, Parle M. Effect of Anwala churna (Emblica officinalis GAERTN.): an ayurvedic preparation on memory deficit rats. Yakugaku Zasshi 2007;127(10):1701-1707

28 Glenner GG, Wong CW. Alzheimer's disease: initial report of the purification and characterization of a novel cerebrovascular amyloid protein. Biochem Biophys Res Commun 1984;120(03): 885-890

29 Lin WT, Chen RC, Lu WW, Liu SH, Yang FY. Protective effects of low-intensity pulsed ultrasound on aluminum-induced cerebral damage in Alzheimer's disease rat model. Sci Rep 2015;5:9671. Doi: 10.1038/srep09671

30 Thippeswamy AH, Rafiq M, Viswantha GLS, Kavya KJ, Anturlikar SD, Patki PS. Evaluation of Bacopa monniera for its synergistic activity with rivastigmine in reversing aluminum-induced memory loss and learning deficit in rats. J Acupunct Meridian Stud 2013;6(04):208-213

31 Auti ST, Kulkarni YA. Neuroprotective effect of cardamom oil against aluminum induced neurotoxicity in rats. Front Neurol 2019;10:399

32 Matsubara E, Ghiso J, Frangione B, et al. Lipoprotein-free amyloidogenic peptides in plasma are elevated in patients with sporadic Alzheimer's disease and Down's syndrome. Ann Neurol 1999;45 (04):537-541

33 Fukumoto H, Tennis M, Locascio JJ, Hyman BT, Growdon JH, Irizarry MC. Age but not diagnosis is the main predictor of plasma amyloid beta-protein levels. Arch Neurol 2003;60(07):958-964

34 Liu HC, Chiu MJ, Lin CH, Yang SY. Stability of Plasma Amyloid- $\beta$ 1-40, Amyloid- $\beta$ 1-42, and Total Tau Protein over Repeated Freeze/Thaw Cycles. Dement Geriatr Cogn Disord Extra 2020;10(01):46-55 